\title{
Spectroscopic Studies of Food Colorings
}

\author{
Patrick Gräb*, Ekkehard Geidel \\ Didactics of Chemistry, Julius-Maximilians-University Würzburg, 97074 Würzburg, Germany \\ *Corresponding author: patrick.graeb@uni-wuerzburg.de
}

Received January 13, 2019; Revised February 24, 2019; Accepted April 01, 2019

\begin{abstract}
In chemical education, it is often a challenge to understand the basic principles of spectroscopic techniques due to missing connections to the real world. Therefore, the present contribution offers context-based applications of UV/Vis spectroscopy for analytics of food colorings with which learners can improve their skills regarding this method. The spectroscopic determination of food colorings seems to be a promising approach due to the long tradition and omnipresence of dyes in supermarket products. The therefor-required spectral data for commonly used dyes are provided for educational usage. Qualitative and quantitative analytics of food colorings in four different lemonades and chocolate beans have been used to introduce learners to important analytical techniques like sample preparation or elimination of confounding factors. These analytics also display the limitations of the method in the visible range of light in the case of tartrazine and curcumin. By applying Lambert-Beer-Bouguer's Law in different variations, typical calculations of concentrations can be studied in quantitative analyses. The studied food samples demonstrate the different usage of food colorings depending on the country of sale. Finally, a 3D-printable low-cost photometer suitable for the discussed quantitative analytics in educational contexts is presented.
\end{abstract}

Keywords: UV/Vis spectroscopy, quantitative analysis, food colorings, context-based teaching, low-cost photometer

Cite This Article: Patrick Gräb, and Ekkehard Geidel, "Spectroscopic Studies of Food Colorings." World Journal of Chemical Education, vol. 7, no. 2 (2019): 136-144. doi: 10.12691/wjce-7-2-13.

\section{Introduction}

In the field of chemical education, the understanding of individual topics of physical chemistry in general and of modern spectroscopic methods in particular are highly demanding challenges. One of the possible entrance strategies for learners with a relatively low prior knowledge is to introduce spectroscopic techniques on a phenomenological basis in connection with context-based experiments [1]. In general, spectroscopic techniques have been proven to be one of the most powerful tools for solving problems encountered in qualitative and quantitative analytical chemistry. The techniques in the infrared range of electromagnetic radiation (wavelength from about $780 \mathrm{~nm}$ to $1 \mathrm{~mm}$ ) such as, e.g. infrared spectroscopy, Raman-spectroscopy or inelastic neutron scattering are well suited and established to determine molecular structures (cf., e.g. [2]). In contrast, the main applications of spectroscopy in the ultraviolet and visible region (wavelength range $10-780 \mathrm{~nm}$ ) are in the field of quantitative analyses (cf., e.g. [3]). For such UV/Vis spectrometric studies, the key-equation relating the absorbance $A$ to the concentration $c$ of the analyte of interest is the Lambert-Beer-Bouguer Law,

$$
A=\varepsilon_{\lambda} \cdot c \cdot d
$$

wherein $\varepsilon_{\lambda}$ stands for the wavelengths dependent attenuation coefficient and $d$ for the path length of radiation through the sample. Eq. 1 is strictly valid only for monochromatic light, low concentrated solutions (usually $c<0.01 \mathrm{~mol} \cdot \mathrm{l}^{-1}$ ), and a homogenous distribution of the analyte in the solution $[4,5]$.

In this contribution, in a first step we focus on quantitative analyses exemplarily for food colors. The coloration of soft drinks and candies with synthetic and natural dyes have been chosen as examples to connect everyday life experience with chemistry-related topics. Even if scientific topics are of low interest for learners, one can increase their motivation by combining those topics with relevant contexts [6]. Such context-based learning is known to raise the interest and emotional valence when dealing with chemical or interdisciplinary scientific problems (cf., e.g., [7,8,9]). However, the use of supermarket products in chemical education is often connected with some additional problems. This is due to the inherently complex composition of the products and the unknown processing procedures. Otherwise, the process of solving these problems can be seen as an opportunity for learners to get used to the challenges in analytical chemistry and research.

In a second step, we are pursuing possibilities and limitations using a low-cost spectral photometer in food analyses for educational purpose, e.g. in hands-on courses. Measuring instruments are indispensable for experiments in physical chemistry. Yet, in general, they are unaffordable in large quantities for educational establishments. This is why low-cost instruments are on the rise (cf., e.g. [1,10]). Especially in quantitative analyses, a simple spectral 
photometer that detects single but specific wavelengths may be sufficient. For usage in practical courses, a little compact setup for measuring light transmission of diodes through a solution in a cuvette has been manufactured using a $3 \mathrm{D}$ printer.

\section{Studies of Food Colorings}

\subsection{Background Information}

Most people eat with the eye first. Consequentially, the color of food plays an important role ever since our ancestors lived thousands of years ago. Back then, color was one of the main features to decide whether food was edible or toxic. Nowadays this decision is not necessary anymore for most people. Today's food should look as appealing as possible to consumers which is guaranteed by adding additional or artificial coloring [11]. The coloration of food, especially of candy, has a long tradition and can be traced back to the ancient Egyptians around $1500 \mathrm{BC}$. There, natural products like saffron or plant extracts were used as dyes [12]. This type of natural food coloring was not affordable for common people, which changed initially with industrialization. Due to the partly unsavory change of color during the processing of food, it was necessary to recolor food with dyes under good economic conditions. Because no general regulations existed, the use of toxic, inorganic salts like lead chromate or copper sulfate was prevalent throughout the $19^{\text {th }}$ century [12]. With the banning of harmful ingredients and colors in Europe (England: 1875, Germany: 1887) and the United States (1906), there was a huge demand of new food dyes [13]. A milestone was a new synthesis technology based on the invention of the first synthetic dye "mauveine" by William Henry Perkin in 1856 which lead to a wide range of synthetic coal-tar colors [12]. These new artificial food dyes replaced not only hazardous inorganic salts but also natural colorants due to their low manufacturing costs, superior coloring properties, and economical usage in products [11].

With the rise of self-service supermarkets, mass production, and transparent packaging the need for standardizing the colors of food was established [13]. In addition, food manufacturers realized the immense economic influence of food colorings due to their psychosocial effects such as color-flavor interactions (cf., e.g., [14]) which lead to a wide spread of synthetic dyes in food in the $20^{\text {th }}$ century. However, the food manufacturers were under pressure since the beginning of the $21^{\text {st }}$ century, due to an upcoming discussion about the harmfulness of artificial dyes [15]. A key moment for the renunciation of artificial food dyes was the Southampton study of McCann et al. [16], which linked hyperactivity in children to artificial colors. In a consequence of the study, food containing specific artificial dyes must be tagged with a warning label in the European Union (EU) since July 2010 [15].

Nowadays the dyes from the Southampton study "have been virtually eliminated" [[17], p. 81] in the EU and food manufactures have the challenging task to replace artificial dyes with natural ones without a loss of quality.

\subsection{Classification and Chemical Properties of Food Colorings}

The use of dyes in food is regulated by each individual country, which leads to partially different definitions, nomenclature, and approvals. In the EU, each approved color additive is listed and labeled with an E-number. There are 40 listed color additives with E-numbers from E100 to E180 [11]. In contrast to that, in the United States (US) there are color additives certified by the Federal Food, Drug and Cosmetic Act (FD\&C) and those exempt from certification process [11].

Although both regulations are different, there is a large overlap for the used dyes. The dyes can be classified due to their chemical properties and origin into three categories:

Natural dyes have their origin in plants or animals. However, neither in the EU nor the US provide a universally accepted definition of the term "natural" $[11,15]$. Against common-sense consumers' expectations, many of these are produced synthetically. In this contribution, we studied carotenes, chlorophylls, and curcumin in food. Carotenes, the most important natural dyes, are tetraterpenes with 9-11 conjugated double bonds. Often, several different dye pigments can be found in the same plant, which makes natural dyes to sophisticated mixtures of colorants [18].

Artificial dyes, however, can be synthetized in a high chemical purity. The main feature is their stable and high color intensity [11]. The majority of artificial colorings are azo dyes (e.g. tartrazine or allura red), which all contain the characteristic $-\mathrm{N}=\mathrm{N}-$ azo group. The remaining artificial dyes can be classified as either triphenylmethane (e.g. brilliant blue) or quinoline dyes (e.g. indigo carmine) [18].

Inorganic pigments like titanium dioxide or metals like silver or gold are less common than natural or artificial dyes. However, titanium dioxide is sometimes used for bleaching effects - especially in candies [18].

The structures of all food colorings studied in this contribution can be found in an interactive table [19].

\subsection{Determination of Attenuation Coefficients of Commonly Used Food Dyes}

\subsubsection{Method}

In order to be quantitatively analyzable in food by spectrophotometry, dyes must absorb radiation in the $\mathrm{UV} / \mathrm{V}$ is region. This absorption must be distinguishable from other species in the sample and from the solvent. That is why, in a first step, the UV/Vis spectra of 21 widespread dyes have been recorded to obtain the wavelengths of their maximum absorbance $\lambda_{\max }$. In a second step, using Lambert-Beer-Bouguer's Law (Eq. 1), a calibration curve has to be constructed for quantitative spectrometric analysis. Therefore, the absorbance $A$ at $\lambda_{\max }$ (corrected by subtracting the absorbance of the blank) is plotted against the concentration in a series of dye standards with different concentrations. In a third step, a linear calibration function can be generated from the standard curve by least squares fit. The concentration of 
the series of standards should be in the same range as the estimated concentration of the dye in the food because an extrapolation does not allow valid conclusions. As a last step, the slope of the linear calibration function can be identified as attenuation coefficient $\varepsilon$ at $\lambda_{\max }$, which is essential to further quantitative analyses of dyes in food.

Most spectral photometers used for quantitative studies in educational framework can measure absorbance only non-dispersive at specific wavelengths (cf. section 4). Therefore, attenuation coefficients $\varepsilon_{\lambda}$ for all measured wavelengths $\lambda$ were determined to ensure the use of such devices.

For a particular wavelength $\lambda$, the slopes of calibration curves can be calculated by using Eq. 2, which combines Lambert-Beer-Bouguer's Law (Eq. 1) with a linear least squares fit:

$$
\varepsilon_{\lambda}=\frac{\sum_{i=1}^{9}\left(A_{\lambda, i}-\overline{A_{\lambda}}\right) \cdot\left(c_{i}-\bar{c}\right)}{d \cdot \sum_{i=1}^{9}\left(c_{i}-\bar{c}\right)^{2}} .
$$

In Eq. 2, $A_{\lambda, i}$ stands for the absorbance of the $\mathrm{i}^{\text {th }}$ sample of the dilution series with concentration $c_{i}, \overline{A_{\lambda}}$ is the arithmetic average absorbance over all nine samples at $\lambda$, and $\bar{c}$ is the arithmetic average concentration of the dilution series. The path length $d$ of radiation through the samples was $1 \mathrm{~cm}$ in all measurements.

\subsubsection{Apparatus and Reagents}

Absorbance measurements for the determination of attenuation coefficients were made on a Specord 50 (Analytik Jena) UV/Vis spectrometer. The spectra were recorded with a spectral resolution of $1 \mathrm{~nm}$. The pure dyes were obtained from ExtraChem and Waldeck - German manufactures of food colorings - and are listed in Table 1.

\subsubsection{Procedure}

Three portions of each dye were weighed out, added to a $50 \mathrm{ml}$ graduated flask and filled up with solvent. In the case of chlorophyll, the solvent was hexan-1-ol. In the case of curcumin it was propan-2-ol and in all other cases it was distilled water. This procedure generated three standard samples, which were diluted again three times. In total, a dilution series containing nine samples with known concentrations was made for each dye. Finally, a ninepoint calibration was calculated.

\subsubsection{Results}

All attenuation coefficients were calculated using the method described above. The values for $\lambda_{\max }$ of each studied dye are listed in Table 1. Coefficients for all other measured wavelengths can be found in an interactive table [19] together with the wavelength dependence of the attenuation coefficients of each dye $(\varepsilon(\lambda)$-spectra).

Attenuation coefficients are the most important factors for quantitative routine analytics in the UV/Vis region. Moreover, the determination with a calibration curve of a dilution series is a basic procedure when using spectroscopic techniques. It is worthwhile for learners to get experience with this procedure. However, in an educational context, attenuation coefficients are often difficult to determine due to the high time exposure and the need of expensive reference chemicals. Therefore, the given attenuation coefficients are especially useful for the efficient quantitative analyses of foods with different colorings particularly in practical courses.

Table 1. Studied food colorings with recorded absorbance maxima and calculated attenuation coefficients

\begin{tabular}{|c|c|c|c|}
\hline Dye & E-No. & $\lambda_{\max }[\mathrm{nm}]$ & $\varepsilon$ at $\lambda_{\max }\left[1 \cdot \mathrm{mol}^{-1} \cdot \mathrm{cm}^{-1}\right]$ \\
\hline Allura Red ${ }^{\dagger}$ & E129 & 502 & 22261 \\
\hline Amarantht+ & E123 & 522 & 21869 \\
\hline Apocarotenal & E160e & $464^{\mathrm{a}}$ & $316746^{\mathrm{a}}$ \\
\hline Azorubinet & E122 & 516 & 20097 \\
\hline$\beta$-Carotene ${ }^{\dagger}$ & E160a & 464 & 896 \\
\hline Betanin ${ }^{\dagger}$ & E162 & 531 & 171 \\
\hline Brilliant Bluet & E133 & 630 & 100661 \\
\hline Brown $\mathrm{HT}^{+}$ & E155 & 463 & 18367 \\
\hline Capsanthin ${ }^{\dagger}$ & E160c & 496 & 1542 \\
\hline Carminet+ & E120 & 518 & 3785 \\
\hline Chlorophyllt+ & E140 & 424 & 20010 \\
\hline Curcumin ${ }^{\dagger}$ & E100 & 430 & 50765 \\
\hline Erythrosine ${ }^{\dagger}$ & E127 & 527 & 79099 \\
\hline Green $\mathrm{S}^{+}$ & E142 & 635 & 86840 \\
\hline Indigo Carminet+ & E132 & 610 & 19445 \\
\hline Lutein ${ }^{\dagger}$ & $\mathrm{E} 160 \mathrm{~b}$ & 452 & 546 \\
\hline Patent Blue $\mathrm{V}^{\dagger}$ & E131 & 638 & 101460 \\
\hline Ponceau 4R+t & E124 & 507 & 19892 \\
\hline Quinoline Yellowt+ & E104 & 413 & 30604 \\
\hline Riboflavin ${ }^{\dagger}$ & E101 & 445 & 9811 \\
\hline Sunset Yellow ${ }^{+\dagger}$ & E110 & 482 & 20165 \\
\hline Tartrazine ${ }^{\dagger}$ & E102 & 428 & 22974 \\
\hline
\end{tabular}

Dyes were obtained from +ExtraChem or ++Waldeck.

a Data taken from [20].

\section{Exemplary Analytics of Dyes in Food}

Most food dyes are used to color confectioneries and beverages. Children and teenagers are often the target group of such colorful products. Their presence in the everyday-life of underaged learners can be utilized as a trigger for motivation (catch-factor). Considering that sugary food is often involved in nutrition debates, a closer examination of their ingredients may be appropriate for learners. Additional to daily exposure limits for sugar, there is also an acceptable daily intake (ADI) for most dyes. The popularity of colorful supermarket products justifies quantitative studies in an educational context with respect to the ADI.

Beside the motivational effect, the analysis of supermarket products might be a chance for learners to train special skills like sample preparation and critical consideration of recorded data. Therefore, the studied foods should be a part of the "real world" but should also illustrate the challenges of spectroscopic techniques.

\subsection{Natural vs. Artificial - Orange Colorings of Mango Lemonades}

Consumer' expectations about color intensity in foodstuffs is often a matter of mentality. Thus, vivid 
colors in sodas are accepted for example in Mediterranean countries and the US but are "in fact undesirable in central and northern Europe where they are perceived as being too artificial" [[11], p. 6]. That leads to the strange situation that sometimes the same food is colored differently depending on the country of sale.

In this contribution, two mango-flavored lemonade samples from the same brand (Coca-Cola) but from different countries are analyzed both qualitatively and quantitatively. On the one hand, the US version is colored with the artificial dye sunset yellow (Yellow No. 6), a water-soluble azo dye with an orange-yellow hue. On the other hand, the EU version is colored with natural carotenes (E160a), whose main component is $\beta$-carotene. Additionally, the EU sample is more turbid compared to the US sample, due to the preparation of $\beta$-carotene. Like most natural dyes, $\beta$-carotene is not water-soluble. Its application in food requires a special preparation called encapsulation. Encapsulation is a useful tool to entrap a substance like a dye within a carrier material [21]. In most cases, the dye is spray-dried on carrier materials like polysaccharides or gum arabic. In fact, there is no solved $\beta$-carotene in the EU variant but a colloidal suspension of carrier-dye particles. Absorbance measurements of suspensions are challenging due to additional scattering of light. Therefore, it is necessary to minimize confounding scattering factors (see below).

\subsubsection{Experimental Procedure}

In the first step, two samples of $20 \mathrm{ml}$ were taken from each lemonade. The carbonated beverages were degassed by shaking in a separation funnel to avoid bubble formation in the cuvettes.

In a second step, a Carrez-clarification was made to reduce the turbidity, especially in the EU variant. The benefit thereby is, that colloids are precipitated but dyes are not adsorbed by the sediment [22]. For the clarification, 0.2 $\mathrm{ml}$ of each Carrez I (aqueous solution of potassium hexacyanidoferrate (II) ) and Carrez II (aqueous solution of zinc acetate) were added to the samples. The sediment was filtrated and washed with water. Afterwards, the colored filtrate was concentrated with a rotary evaporator and refilled with water to the original sample volume. Finally, the absorbance spectra of the samples were recorded in the visible range.

\subsubsection{Results and Discussion}

The absorbance spectra of the mango-flavored lemonades, as shown in Figure 1, allow qualitative predications.

As can be seen, the two lemonades are obviously colored with different dyes. The US sample has its absorbance maximum at $482 \mathrm{~nm}$. The absorbance maximum is slightly red-shifted compared to the one of the EU sample, which is located at $454 \mathrm{~nm}$. As a result, the US sample appears more orange whereas the color effect of the EU sample is rather yellow. This is due to the respective complementary colors.

The absorbance of the US lemonade is generally higher than its EU-counterpart, which explains the more intensive hue. However, learners could misinterpret the higher color intensity with a larger amount of dye used. A quantitative analysis of the recorded data is necessary to avoid such a misconception. Valid quantitative propositions can only be made by including the attenuation coefficients of the dyes. The required information is summarized in Table 2 together with the results from the quantitative analysis.

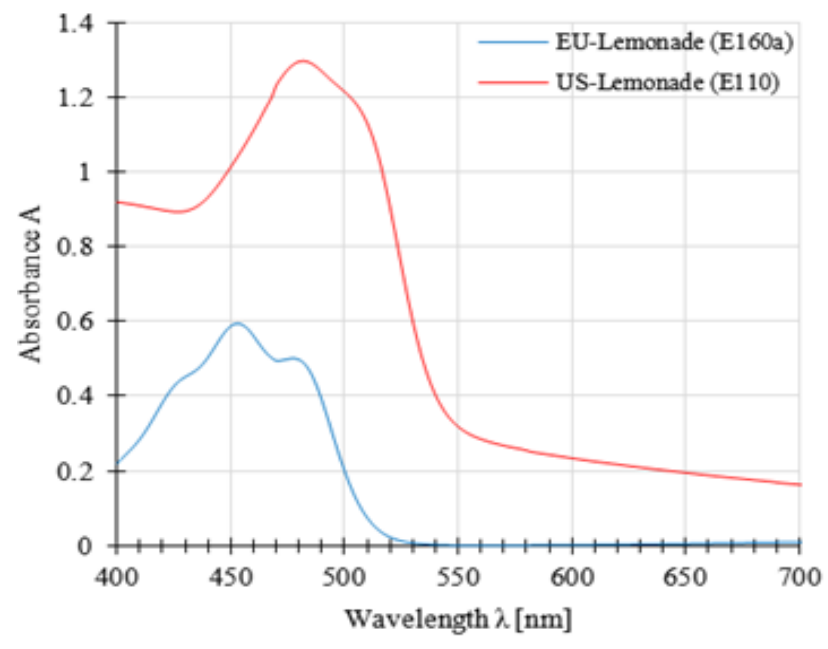

Figure 1. Absorbance spectra of mango-flavored lemonades by the same brand but purchased in different countries

Table 2. Spectral information, molar masses, and calculated mass concentrations of dyes in mango-flavored lemonades

\begin{tabular}{|c|c|c|c|c|}
\hline Sample & $A_{\lambda}$ & $\begin{array}{c}\varepsilon_{\lambda} \\
{\left[1 \cdot \mathrm{mol}^{-1} \cdot \mathrm{cm}^{-1}\right]}\end{array}$ & $\begin{array}{c}M_{\text {Dye }} \\
{\left[\mathrm{g} \cdot \mathrm{mol}^{-1}\right]}\end{array}$ & $\begin{array}{c}\rho_{\text {Dye }} \\
{\left[\mathrm{mg} \cdot l^{-1}\right]}\end{array}$ \\
\hline EU & 0.5941 & 875 & 536.89 & 364.5 \\
\hline US & 1.2975 & 20165 & 452.36 & 29.1 \\
\hline
\end{tabular}

Eq. 1 yields the molar concentrations of dyes in the studied beverages. However, the molar concentration $c$ of each dye was converted to a mass concentration $\rho$ with Eq. 3 , due to a better comparability:

$$
\rho=c \cdot M_{D y e}=\frac{A_{\lambda}}{\varepsilon_{\lambda} \cdot d} \cdot M_{D y e} .
$$

The quantitative analysis shows that the amount of used dye is smaller in the US sample although its color is more intense.

Nevertheless, especially the mass concentration of $\beta$-carotene should be evaluated carefully. In general, the color properties of natural dyes are inferior compared to those of artificial dyes, which results in larger amounts of natural dyes in food. However, one possible explanation for the exceptional high mass concentration of $\beta$-carotene might be the encapsulation of the dye. Despite the clarification, the EU sample was still slightly turbid, which leads to a confounding scattering effect. Hence, learners should always evaluate their conclusions carefully, especially in routine analytics.

\subsection{Additive Color Blending in Woodruff Lemonades}

Many color-flavor combinations are intuitive. For example in Germany, the traditional culinary code dictates that green lemonade is likely to be woodruff-flavored. Actually, natural woodruff is not used anymore in industrial foods due to health issues discussed in the 1970s [18]. Consequentially, artificially flavored and colored imitations were developed. The rich green hue of woodruff lemonades is predestined for educational food 
dye analysis. The green color can arise either directly through green colorings like chlorophyll (E140), or indirectly by additive color blending of yellow and blue dyes. The first variant is realized in the Ahoj woodruff-flavored drink from Frigeo (Germany). Monolith West GmbH (Germany) followed the second strategy in their Tarhun (original: TAРХУН) lemonade. This woodruff-flavored lemonade contains a mixture of tartrazine (E102) and patent blue V (E131) and is produced purposeful for the Russian market and its consumers. The two lemonades are analyzed quantitatively and qualitatively with respect to additive color blending.

\subsubsection{Experimental Procedure}

At first, the two different dyes in the Tarhun lemonade were isolated by flash column chromatography to illustrate the additive color blending. The column was filled with silica gel (stationary phase). The eluent (mobile phase) consisted of a mixture of butan-1-ol (43\%), ammonia water $(36 \%)$, distilled water $(14 \%)$, and ethanol (7\%). A sample of $20 \mathrm{ml}$ taken from the Tarhun lemonade was concentrated with a rotary evaporator before it was applied to the column. After isolating, the yellow and the blue fractions were both concentrated to dryness and refilled with water to the original sample volume.

The chlorophyll contained in $20 \mathrm{ml}$ Ahoj lemonade was transferred to the solvent hexan-1-ol by liquid-liquid extraction. Afterwards, the sample was concentrated to the original sample volume. As a last step, absorbance spectra of both lemonades and both isolated fractions were recorded in the visible range.

\subsubsection{Results and Discussion}

The absorbance spectra of both lemonades, as shown in Figure 2, display a high absorbance in the blue and red region of light, which causes their green appearance. The absorbance spectrum of Ahoj lemonade is typical for the dye chlorophyll. The well-known Soret-band is located at $408 \mathrm{~nm}$ whereas the Q-band is located at $628 \mathrm{~nm}$. The location of these bands can vary due to the diverse composition of chlorophyll. The leaf pigment chlorophyll is no pure substance but a collective for the substance class of chlorophylls. All of them have a similar structure containing a chlorine or a porphyrin ring. The most common chlorophylls are chlorophyll a and chlorophyll b, which differ from each other only in one functional group [18]. When used as food coloring, chlorophyll is extracted from plants and often is processed to increase its water solubility.

The Tarhun lemonade, however, is colored by using two different dyes. In fact, the absorbance spectra of
Tarhun results from the addition of both single spectra (E102 \& E131), which is clarified in Figure 2. The spectrum has two local absorbance maxima at $418 \mathrm{~nm}$ and $640 \mathrm{~nm}$. The first one is caused by the dye tartrazine, which has an absorbance maximum at $426 \mathrm{~nm}$ in the isolated fraction. The blue dye (patent blue V) is responsible for the second absorbance maximum of the Tarhun spectrum at $640 \mathrm{~nm}$ on the one hand. On the other hand, it causes the $8 \mathrm{~nm}$ difference between the first absorbance maxima of Tarhun and the absorbance maximum of the yellow fraction due to its high background around $404 \mathrm{~nm}$.

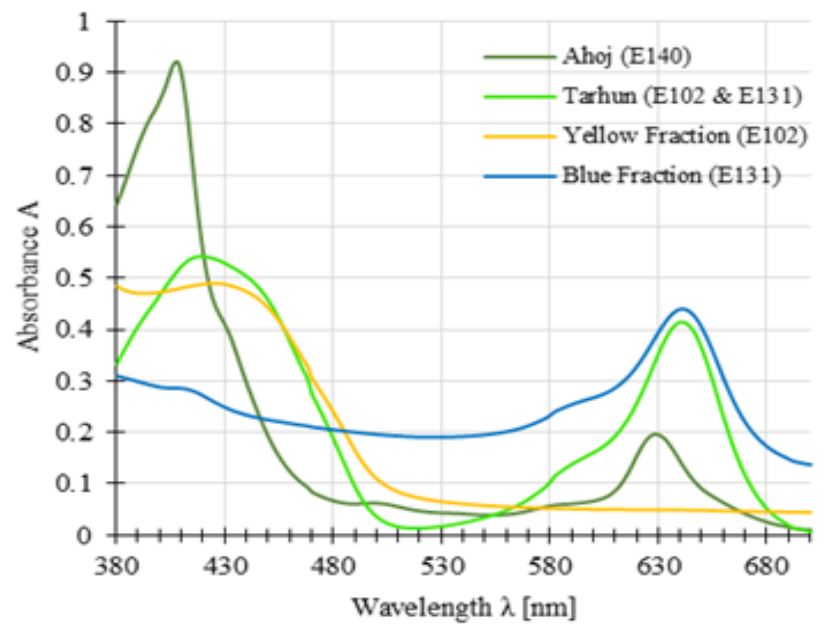

Figure 2. Absorbance spectra of Ahoj and Tarhun woodruff-flavored lemonades together with the spectra of the isolated chromatographic fractions of Tarhun containing the dyes tartrazine (E102) and patent blue $\mathrm{V}(\mathrm{E} 131)$ respectivly

The discussion of the absorbance spectra, especially of quantitative aspects, introduces learners to the limitation of Lambert-Beer-Bouguer's Law (Eq. 1). In fact, Eq. 1 is only valid for exactly one analyte. If a sample like Tarhun contains two or more analytes, the Lambert-Beer-Bouguer Law for multiple components $N$, as shown in Eq. 4 , has to be used to determine the analytes' concentrations:

$$
A_{\lambda}=\sum_{i=1}^{N} A_{\lambda_{i}}=d \cdot \sum_{i=1}^{N} \varepsilon_{\lambda, i} \cdot c_{i} .
$$

If the sample contains $N$ components, then the absorbance should be determined at $N$ different wavelengths to get a solvable system of linear equations. The results of the quantitative analyses of the two woodruff-flavored lemonades and the isolated fractions of Tarhun lemonade are summarized in Table 3.

Table 3. Spectral information, molar masses, and calculated mass concentrations of dyes in woodruff-flavored lemonades and in isolated fractions of Tarhun lemonade

\begin{tabular}{|c|c|c|c|c|c|}
\hline Sample (Dye) & $\lambda[\mathrm{nm}]$ & $A_{\lambda}$ & $\begin{array}{c}\varepsilon_{\lambda} \\
{\left[1 \cdot \mathrm{mol}^{-1} \cdot \mathrm{cm}^{-1}\right]}\end{array}$ & $\begin{array}{c}M_{\text {Dye }} \\
{\left[\mathrm{g} \cdot \mathrm{mol}^{-1}\right]}\end{array}$ & $\begin{array}{c}\rho_{\text {Dye }} \\
{\left[\mathrm{mg} \cdot 1^{-1}\right]}\end{array}$ \\
\hline Ahoj (E140) & 408 & 0.9205 & 19134 & $900.5^{\mathrm{a}}$ & 43.3 \\
\hline Tarhun (E102) & $\begin{array}{l}418 \\
640\end{array}$ & $\begin{array}{l}0.5429 \\
0.4149\end{array}$ & $\begin{array}{c}22501 \\
69\end{array}$ & 534.37 & 12.0 \\
\hline Tarhun (E131) & $\begin{array}{l}418 \\
640 \\
\end{array}$ & $\begin{array}{l}0.5429 \\
0.4149 \\
\end{array}$ & $\begin{array}{c}9508 \\
101060\end{array}$ & 582.66 & 2.4 \\
\hline Tarhun, yellow fraction. (E102) & 426 & 0.4915 & 22964 & 534.37 & 11.4 \\
\hline Tarhun, blue fraction (E131) & 640 & 0.4395 & 101060 & 582.66 & 2.5 \\
\hline
\end{tabular}

${ }^{a}$ Arithmetic average of the molar masses of chlorophyll a and $b$. 
Learners could draw several conclusions from the results. At first, the applied amount of natural dye in Ahoj lemonade is higher than the amount of artificial dyes in Tarhun. This can be traced back again to the better color properties of artificial dyes. A second conclusion is that an absorbance spectrum can result in several single spectra due to additive color blending. However, the existence of two dyes is not apparent from the original spectrum. A separation method like column chromatography can reveal their existence but the method is costly and timeconsuming. An alternative quantitative analysis with Eq. 4 avoids further sample preparation and is an economical method for routine analytics.

\subsection{Colorful Dyes in Chocolate Beans}

As a third example to demonstrate the practical use of UV/Vis spectroscopy for analytics in a "real-world" application, M\&M's ("Mars \& Murries") chocolate beans (from Mars Inc.) were selected. This colorful chocolate candy was first introduced in the US in 1941 and is sold worldwide in over 100 countries today. Each bag of M\&M's traditionally always consists of a color mix of at least five different colors. This turns it into a well-suited candidate for food dye analysis. Noteworthy, in mathematical education for students the color distribution of M\&M's candies is a popular experiment in introductory courses to teach probability and statistics by using real data [23].

Besides the gradual change of color distribution, the used dyes have also changed. A well-known story is the disappearance of the red M\&M in the 1970s as a consequence of banning the dye amaranth (Red No. 2) in the US. Today, the red chocolate bean is available again as one of the six most typical colors. However, different dyes are used depending on the country of sale. This is similar to the studied mango-flavored lemonades (cf. section 3.1.).

The spectral analysis of samples from different countries enables learners to study a large range of food colorings. Thereby, qualitative varieties between the samples are visible by the bare eyes in some cases but in most cases, the used dyes can only be distinguished by spectroscopic methods.

\subsubsection{Experimental Procedure}

Three chocolate beans of each color were weighed once for the EU product and once for the US product. This generated twelve different samples in total. The brown samples were discarded because the brown chocolate beans from the EU do not contain any food dyes. The dyes in the colorful coatings were solved in distilled water. The EU samples contain a white coating of titanium dioxide under the colored film. To reduce the turbidity caused by the titanium dioxide particles, a Carrez-clarification was made (cf. section 3.1.1.). Afterwards, the colored solutions were filled up to a volume of $50 \mathrm{ml}\left(V_{\text {Sample }}\right)$ with distilled water. Afterwards, absorbance spectra of the remaining ten samples were recorded in the visible range.

\subsubsection{Results and Discussion}

The analysis and discussion of the recorded absorbance spectra of the ten M\&M's samples is similar, which constitutes a good exercise for learners in terms of repetition. Alternatively, at this point, learners can be introduced to different elimination techniques of the influence of titanium dioxide. This introduction could contain methods like column chromatography or compensation of matrix effects in spectroscopic experiments.

In this contribution, the evaluation of the absorbance spectra of the yellow samples is discussed exemplarily. In fact, the absorbance spectra, as shown in Figure 3, also display the limits of UV/Vis spectroscopy in the field of qualitative analytics.

The yellow chocolate beans purchased in the EU are colored with the natural dye curcumin (E100), whereas the US version is colored with the azo dye tartrazine (E102). Even if the structures of curcumine and tartrazine - as illustrated in Figure $4-$ are completely different, their $\mathrm{UV} / \mathrm{V}$ is spectra are more or less similar. Consequently, both dyes cannot be distinguished by spectroscopy in the visible range. This is a typical example that shows learners phenomenological that UV/Vis spectra alone are not sufficient for qualitative content analysis.

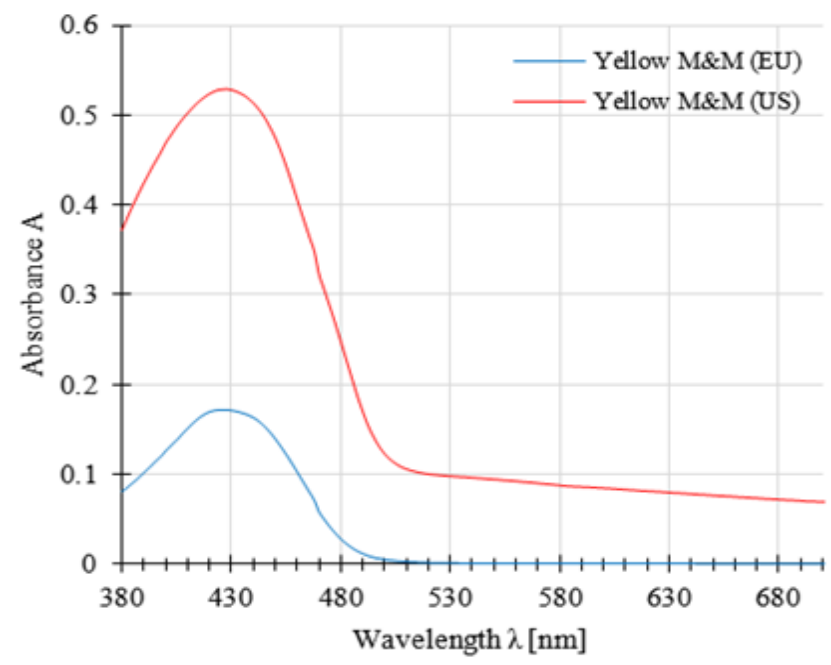

Figure 3. Absorbance spectra of the yellow M\&M's samples purchased in the EU and the US<smiles>COc1cc(/C=C/C(=O)CC(=O)/C=C/c2ccc(O)c(OC)c2)ccc1O</smiles><smiles></smiles>

Figure 4. Structures of curcumin (E100) and tartrazine (E102) 


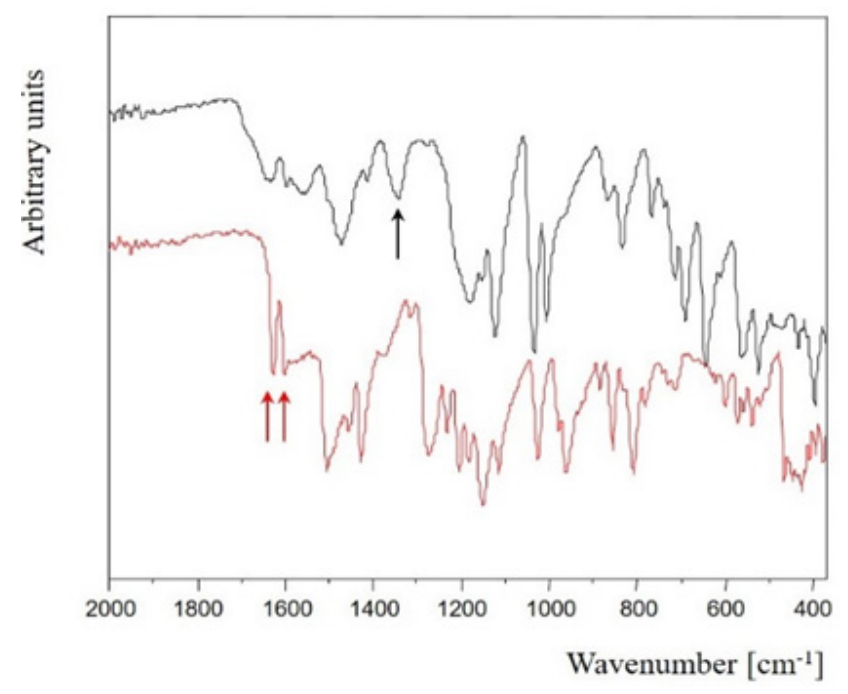

Figure 5. Infrared spectra of tartrazine (black) and curcumin (red)

In this case, additional information is required, e.g., from infrared spectra and their interpretation based on the empirical approach of characteristic group frequencies. Therefore, the infrared spectra of solid tartrazine and curcumin - presented in Figure 5 in the range 2000-400 $\mathrm{cm}^{-1}$ - were recorded using a Bruker ALPHA ATR-FTIR-spectrometer. The observed spectra are in good overall agreement with the IR transmission spectra recorded from $\mathrm{KBr}$ wafers of the same colorants [24].

As expected, both infrared spectra are completely different. Tartrazine is a monoazo compound. In the IR spectrum of the dye (black spectrum in Figure 5) a characteristic band at $1343 \mathrm{~cm}^{-1}$ (marked by an arrow) was observed which can be assigned to the $v(-\mathrm{N}=\mathrm{N}-)$ stretching mode of the azo chromophore group [25]. No band was observed in the IR spectrum of curcumin in this region (Figure 5). In the spectrum of solid curcumin as a typical diketone, one would expect bands in the carbonyl stretching region $\left(1800-1650 \mathrm{~cm}^{-1}\right)$. However, no bands were found in this range. Curcumin in the solid state obviously exists only in the enol-form and the bands at 1626 and $1601 \mathrm{~cm}^{-1}$ can be assigned to predominantly mixed $v(\mathrm{C}=\mathrm{C})+v(\mathrm{C}=\mathrm{O})$ and to $v(\mathrm{C}=\mathrm{O})+v(\mathrm{C}=\mathrm{C})$ stretching modes, respectively [26]. On this path, if the vibrational assignment of the bands are known, vibrational spectroscopy may yield valuable information for structure determination of different colorings. Thus, the discussion of the qualitative analysis of the yellow M\&M's samples simultaneously shows learners the limits of UV/Vis spectroscopy and the possibilities of other spectroscopic techniques like IR spectroscopy. For advanced learners this might be an introduction into vibrational spectroscopy.

In order to improve the learners' skills in terms of quantitative routine analytics, the colored chocolate beans are also a suitable application with an everyday-life connection. For the purpose of a better comparability, the molar concentration $c$ of each studied solution calculated with Eq. 1 was converted to a mass fraction $w$ :

$$
w_{\text {Dye }}=\frac{m_{\text {Dye }}}{m_{\text {total }}}=\frac{1}{m_{\text {total }}} \cdot \frac{A_{\lambda} \cdot V_{\text {Sample }} \cdot M_{\text {Dye }}}{\varepsilon_{\lambda} \cdot d} .
$$

In Eq. 5, $m_{\text {total }}$ stands for the total mass of each weighed M\&M's sample and $V_{\text {Sample }}$ for the volume of the colored solutions, made from the color films of the chocolate beans. The calculated mass fractions of the dyes in question are listed in Table 4 together with their spectral information. The molar masses of the food colorings, necessary for the calculation of the mass fractions can be found in an interactive table [19].

Table 4. Spectral information and total masses of the studied chocolate beans samples together with the calculated mass fractions of the containing dyes

\begin{tabular}{|c|c|c|c|c|c|c|}
\hline & $\begin{array}{l}\text { Color } \\
\text { (Dye) }\end{array}$ & $\begin{array}{c}\lambda \\
{[\mathrm{nm}]}\end{array}$ & $A_{\lambda}$ & $\begin{array}{c}\varepsilon_{\lambda} \\
{\left[1 \cdot \mathrm{mol}^{-1} \cdot \mathrm{cm}^{-1}\right]}\end{array}$ & $\begin{array}{c}m_{\text {total }} \\
{[\mathrm{g}]}\end{array}$ & $\begin{array}{c}w_{\text {Dye }} \\
{[\mathrm{mg} / 100 \mathrm{~g}]}\end{array}$ \\
\hline \multirow{6}{*}{ 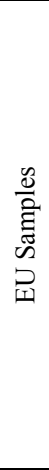 } & $\begin{array}{c}\text { Blue } \\
\text { (E133) }\end{array}$ & 630 & 0.8957 & 100661 & 3.090 & 11.4 \\
\hline & $\begin{array}{l}\text { Green } \\
(\mathrm{E} 100)\end{array}$ & $\begin{array}{l}420 \\
628\end{array}$ & $\begin{array}{l}0.1366 \\
0.0457\end{array}$ & $\begin{array}{c}49025 \\
35\end{array}$ & 3.014 & 1.7 \\
\hline & $\begin{array}{l}\text { Green } \\
\text { (E133) }\end{array}$ & $\begin{array}{l}420 \\
628\end{array}$ & $\begin{array}{l}0.1366 \\
0.0457\end{array}$ & $\begin{array}{c}6664 \\
100133\end{array}$ & 3.014 & 0.6 \\
\hline & $\begin{array}{l}\text { Orange } \\
\text { (E160e) }\end{array}$ & 456 & 0.1122 & 314780 & 3.154 & 0.2 \\
\hline & $\begin{array}{c}\text { Red } \\
(\text { E120) }\end{array}$ & 514 & 0.1058 & 3699 & 3.314 & 21.2 \\
\hline & $\begin{array}{l}\text { Yellow } \\
(\text { E100) }\end{array}$ & 426 & 0.1718 & 50540 & 2.936 & 2.1 \\
\hline \multirow{6}{*}{ 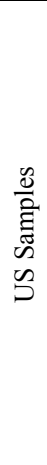 } & $\begin{array}{c}\text { Blue } \\
(\text { E133) }\end{array}$ & 630 & 0.5247 & 100661 & 2.772 & 7.5 \\
\hline & $\begin{array}{l}\text { Green } \\
(\mathrm{E} 102)\end{array}$ & $\begin{array}{l}416 \\
630\end{array}$ & $\begin{array}{l}0.2022 \\
0.1501\end{array}$ & $\begin{array}{c}22299 \\
70\end{array}$ & 2.702 & 8.4 \\
\hline & $\begin{array}{l}\text { Green } \\
\text { (E133) }\end{array}$ & $\begin{array}{l}416 \\
630\end{array}$ & $\begin{array}{l}0.2022 \\
0.1501\end{array}$ & $\begin{array}{c}8790 \\
100661\end{array}$ & 2.702 & 2.2 \\
\hline & $\begin{array}{l}\text { Orange } \\
\text { (E110) }\end{array}$ & 482 & 1.1348 & 20165 & 2.617 & 48.6 \\
\hline & $\begin{array}{c}\text { Red } \\
(\text { E129) }\end{array}$ & 502 & 0.3117 & 22261 & 2.520 & 13.8 \\
\hline & $\begin{array}{l}\text { Yellow } \\
(\text { E102) }\end{array}$ & 428 & 0.5291 & 22974 & 2.870 & 21.4 \\
\hline
\end{tabular}

\section{Low-Cost Photometer for Educational Purposes}

The described context-based applications of UV/Vis spectroscopy are suitable for experiments in hands-on courses. To achieve a good learning effect, the group size should be as small as possible. Best results can be achieved when learners can experiment by themselves. Consequently, there is a steep demand for large numbers of measuring devices. For most educational establishments low-cost techniques are the only feasible solution.

Low-cost spectrometers which learners can setup by themselves, as described in [1], are appropriate when studying their function but often are too inaccurate to run quantitative routine analyses. In the case of quantitative analytics with Lambert-Beer-Bouguer's Law (Eq. 1) the absorbance is normally detected at the wavelength of the absorbance maximum. Therefore, a photometer may be sufficient. Additionally, the setup is simpler and easier to understand for learners because of the reduced number of spectral components. Subsequently, a 3D-printable 
low-cost photometer for educational usage, based on the work of Kvittingen et al. [27], has been developed.

The device is composed of a 3D-printed cuvette holder with an integrated but interchangeable light source and detector (Figure 6).

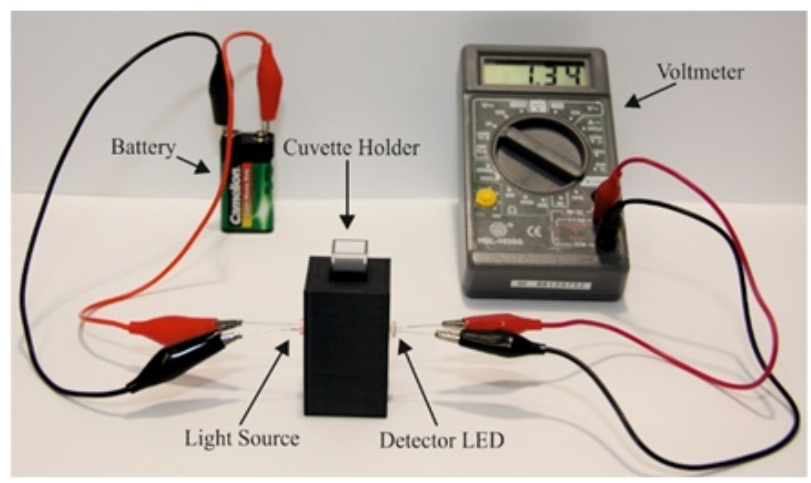

Figure 6. Setup of the low-cost photometer composed of a 3D-printed cuvette holder with integreted LEDs and a voltmeter

The key feature of this low-cost photometer is the use of paired emitter detector diodes, i.e., the application of light emitting diodes (LED) both as light source and as detector. The LED used as light source generates a photocurrent in another LED with the same emission wavelength as the first one [28]. Consequentially, a voltage can be measured by connecting a voltmeter with the detector LED. The measured voltage is proportional to the amount of light, which induces the photocurrent. As a result, the setup can be used as a simple photometer when a sample containing an absorbing analyte is placed between the LEDs.

Table 5. Comparison between the mass concentrations calculated from different recorded data (Specord 50 spectrometer and low-cost photometer)

\begin{tabular}{|c|c|c|c|c|c|c|}
\hline & & \multicolumn{2}{|c|}{$\begin{array}{c}\text { Specord } 50 \\
\text { Spectrometer }\end{array}$} & \multicolumn{2}{|c|}{$\begin{array}{c}\text { Low-Cost } \\
\text { Photometer }\end{array}$} & \multirow[b]{2}{*}{$\begin{array}{c}f \\
{[\%]}\end{array}$} \\
\hline & $\begin{array}{l}\text { Color } \\
\text { (Dye) }\end{array}$ & $\begin{array}{c}\lambda \\
{[\mathrm{nm}]}\end{array}$ & $\begin{array}{c}w_{\text {Dye }} \\
{[\mathrm{mg} / 100 \mathrm{~g}]}\end{array}$ & $\begin{array}{l}\lambda_{\mathrm{LED}} \\
{[\mathrm{nm}]}\end{array}$ & $\begin{array}{c}w_{\text {Dye }} \\
{[\mathrm{mg} / 100 \mathrm{~g}]}\end{array}$ & \\
\hline \multirow{6}{*}{ 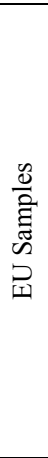 } & $\begin{array}{c}\text { Blue } \\
(\text { E133) }\end{array}$ & 630 & 11.4 & 640 & 10.5 & 8 \\
\hline & $\begin{array}{l}\text { Green } \\
(\mathrm{E} 100)\end{array}$ & $\begin{array}{l}420 \\
628\end{array}$ & 1.7 & $\begin{array}{l}400 \\
640\end{array}$ & 1.5 & 12 \\
\hline & $\begin{array}{l}\text { Green } \\
\text { (E133) }\end{array}$ & $\begin{array}{l}420 \\
628\end{array}$ & 0.6 & $\begin{array}{l}400 \\
640 \\
\end{array}$ & 0.7 & 17 \\
\hline & $\begin{array}{c}\text { Orange } \\
(\mathrm{E} 160 \mathrm{e})\end{array}$ & 456 & 0.2 & 460 & 0.2 & 0 \\
\hline & $\begin{array}{c}\text { Red } \\
(\mathrm{E} 120)\end{array}$ & 514 & 21.2 & 525 & 18.5 & 13 \\
\hline & $\begin{array}{l}\text { Yellow } \\
(\mathrm{E} 100)\end{array}$ & 426 & 2.1 & 460 & 2.5 & 19 \\
\hline \multirow{6}{*}{ 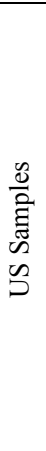 } & $\begin{array}{c}\text { Blue } \\
\text { (E133) }\end{array}$ & 630 & 7.5 & 640 & 5.8 & 23 \\
\hline & $\begin{array}{c}\text { Green } \\
(\mathrm{E} 102)\end{array}$ & $\begin{array}{l}416 \\
630\end{array}$ & 8.4 & $\begin{array}{l}400 \\
640\end{array}$ & 7.5 & 11 \\
\hline & $\begin{array}{c}\text { Green } \\
\text { (E133) }\end{array}$ & $\begin{array}{l}416 \\
630\end{array}$ & 2.2 & $\begin{array}{l}400 \\
640\end{array}$ & 2.0 & 9 \\
\hline & $\begin{array}{l}\text { Orange } \\
\text { (E110) }\end{array}$ & 482 & 48.6 & 460 & 29.1 & 40 \\
\hline & $\begin{array}{c}\text { Red } \\
(\mathrm{E} 129)\end{array}$ & 502 & 13.8 & 525 & 14.2 & 3 \\
\hline & $\begin{array}{l}\text { Yellow } \\
(\mathrm{E} 102)\end{array}$ & 428 & 21.4 & 460 & 18.6 & 13 \\
\hline
\end{tabular}

In fact, the absorbance can be calculated in analogy to Lambert-Beer-Bouguer's Law by using the measured voltage $V$, as shown in Eq 6:

$$
A=-\log \left(\frac{V_{\text {Sample }}}{V_{\text {Blank }}}\right) .
$$

The accuracy of this procedure is adequate and the costs for the setup are low. This makes the photometer suitable for educational usage. However, although several types of LEDs can be purchased, their emission wavelengths do often not coincide with the wavelength of the absorbance maximum of the analyte. Therefore, it is necessary to adjust the attenuation coefficients of the emitted wavelengths of the applied LED by using the interactive table [19] (cf. section 2.3.4.).

To show the accuracy of the photometer setup, a quantitative analysis of the M\&M's samples was made again with the low-cost device. The results are summarized in Table 5 together with the results recorded with a commercial spectrometer (cf. section 3.3.). As can be seen, the deviations $f$ are still acceptable in context of an educational purpose.

\section{Summary and Conclusion}

In this contribution, food colorings have been used to reveal a phenomenological and experimental access to the utilization of UV/Vis spectroscopic techniques in chemical analyses. For this, lemonades and chocolate candies have been chosen as typical examples to connect teaching of analytical procedures with the everyday context of learners. The fact, that the same food is sometimes colored differently depending on the country of sale makes them to well-suited candidates for analytical experiments in hands-on courses. However, food dyes are often natural products and industrial coloring of foods frequently utilizes highly sophisticated techniques like encapsulation. This is connected to additional difficulties and the result should be evaluated carefully. Especially chlorophylls and carotenes are numerous in types, and thus complicate the interpretation of spectral data. In this way, learners can be introduced to the need of additional important analytic techniques like sample preparation or elimination of confounding factors. In addition, the exemplary quantitative analysis of supermarket products demonstrate various applications of Lambert-BeerBouguer's Law. The results of all studied samples are summarized in Table 6. As an important result, a remarkable difference was observed in the usage of dyes depending on the country of sale.

To teach basic principles of quantitative analyses by spectroscopy, the determination of attenuation coefficients for systems with practical relevance - like lemonades or candies - is necessary. Especially the wavelengths dependencies of the attenuation coefficients are a key problem for the implementation in hands-on courses. Therefore, extensive experimental data for attenuation coefficients for food dyes are provided for support as supplementary material [19].

In a final step, a 3D-printable low-cost photometer was developed and tested for spectroscopic studies of food 
colorings. The results are of sufficient accuracy for educational purposes. Therefore, this technique appears to provide an easier access to low-cost spectroscopic experiments in hands-on courses.

Table 6. Summary of the studied food samples with their respective used dyes and determined concentrations

\begin{tabular}{|c|c|c|c|c|}
\hline Sample & Country & $\begin{array}{c}\text { Dye } \\
\text { (E-No.) }\end{array}$ & $\begin{array}{c}w_{\text {Dye }} \\
{[\mathrm{mg} / 100 \mathrm{~g}]}\end{array}$ & $\begin{array}{c}\rho_{\text {Dye }} \\
{\left[\mathrm{mg} \cdot 1^{-1}\right]}\end{array}$ \\
\hline Fanta Mango & US & E110 & - & 29.1 \\
\hline Fanta Mango & $\mathrm{EU}$ & E160a & - & 364.5 \\
\hline Ahoj & $\mathrm{EU}$ & E140 & - & 43.3 \\
\hline Tarhun & EU & $\begin{array}{l}\text { E102 } \\
\text { E131 }\end{array}$ & - & $\begin{array}{l}12.0 \\
2.4 \\
\end{array}$ \\
\hline M\&M's (blue) & US & E133 & 7.5 & - \\
\hline M\&M's (blue) & EU & E133 & 11.4 & - \\
\hline M\&M's (green) & US & $\begin{array}{l}\text { E102 } \\
\text { E133 }\end{array}$ & $\begin{array}{l}8.4 \\
2.2\end{array}$ & - \\
\hline M\&M's (green) & EU & $\begin{array}{l}\text { E100 } \\
\text { E133 }\end{array}$ & $\begin{array}{l}1.7 \\
0.6 \\
\end{array}$ & $\begin{array}{l}- \\
-\end{array}$ \\
\hline M\&M's (orange) & US & E110 & 48.6 & - \\
\hline M\&M's (orange) & EU & E160e & 0.2 & - \\
\hline M\&M's (red) & US & E129 & 13.8 & - \\
\hline M\&M's (red) & EU & E120 & 21.2 & - \\
\hline M\&M's (yellow) & US & E102 & 21.4 & - \\
\hline M\&M's (yellow) & EU & E100 & 2.1 & - \\
\hline
\end{tabular}

\section{Acknowledgements}

The authors thankfully acknowledge Wolfgang Obert for technical support and Maximilian Fest for experimental assistance.

This publication was funded by the German Research Foundation (DFG) and the University of Würzburg in the funding program Open Access Publishing.

\section{References}

[1] Schairer, P., Wagner, S., and Geidel, E., "An Experimental Introduction to Basic Principles of the Interaction of Electromagnetic Radiation with Matter," World Journal of Chemical Education, 6(1), 29-35, Jan. 2018.

[2] Karge, H. G. and Geidel, E., "Vibrational Spectroscopy," in Molecular Sieves - Science and Technology, Berlin, Springer Verlag, 2004, 1-200.

[3] Checchetti, A., "Quantitative Analysis of Alcoholic Drinks. Use of Calibration Curve Method to Determine the Alcoholic Degree of Samples of Paesanella, a Distillate of the Family of Grappa," World Journal of Chemical Education, 3(3), 70-73, May 2015.

[4] Schmidt, W., Optical Spectroscopy in Chemistry and Life Sciences, Weinheim, Wiley-VCH, 2005.

[5] Otto, M., Analytische Chemie, 4th ed., Weinheim, Wiley-VCH, 2011.

[6] Bolte, C., Streller, S., and Hofstein, A., "How to motivate students and raise their interest in chemistry education," in Teaching Chemistry - A Studybook, Rotterdam, Sense Publishers, 2013, 67-95.

[7] Weirauch, K., Lohwasser, K., Fenner, C., and Geidel, E., "Chemie im Kontext weitergedacht - ein Diskussionsbeitrag," in Naturwissenschaftliche Bildung als Grundlage für berufliche und gesellschaftliche Teilhabe, Kiel, 2019, 193-196.
[8] van Vorst, H., Fechner, S., and Sumfleth, E., "Unterscheidung von Kontexten für den Chemieunterricht," Zeitschrift für Didaktik der Naturwissenschaften, 24(1), 167-181, Dec. 2018.

[9] Huntemann, H., Paschmann, A., Parchmann, I., and Ralle, B., "Chemie im Kontext-ein neues Konzept für den Chemieunterricht?," CHEMKON, 6(4), 191-196, Jan. 1999.

[10] Grasse, E. K., Torcasio, M. H., and Smith, A. W., "Teaching UV-Vis Spectroscopy with a 3D-Printable Smartphone Spectrophotometer," Journal of Chemical Education, 93(1), 146-151, Jan. 2016.

[11] Stich, E., "Food Color and Coloring Food: Quality, Differentiation and Regulatory Requirements in the European Union and the United States," in Handbook on Natural Pigments in Food and Beverages, R. Carle and R. M. Schweiggert, Eds. Woodhead Publishing, 2016, 3-27.

[12] Burrows, A., "Palette of Our Palates: A Brief History of Food Coloring and Its Regulation," Comprehensive Reviews in Food Science and Food Safety, 8(4), 394-408, Oct. 2009.

[13] Hisano, A., "The Rise of Synthetic Colors in the American Food Industry, 1870-1940," Business History Review, 90(3), 483-504, 2016.

[14] Levitan, C. A., Zampini, M., Li, R., and Spence, C., "Assessing the Role of Color Cues and People's Beliefs About Color-Flavor Associations on the Discrimination of the Flavor of Sugar-Coated Chocolates," Chemical Senses, 33(5), 415-423, Jun. 2008.

[15] Wrolstad, R. E. and Culver, C. A., "Alternatives to Those Artificial FD\&C Food Colorants," Annual Review of Food Science and Technology, 3(1), 59-77, 2012.

[16] McCann, D. et al., "Food additives and hyperactive behaviour in 3-year-old and 8/9-year-old children in the community: a randomised, double-blinded, placebo-controlled trial," The Lancet, 370(9598), 1560-1567, Nov. 2007.

[17] McAvoy, S. A., "Global Regulations of Food Colors," The Manufacturing Confectioner, 94(9), 77-86, Sep. 2014.

[18] Ebermann, R. and Elmadfa, I., Lehrbuch Lebensmittelchemie und Ernährung, 2nd ed., Wien, Springer-Verlag, 2011.

[19] Gräb, P., "Spectral Data of Food Colorings," 2019. [Online]. Available https://www.chemie.uni-wuerzburg.de/didaktik/lehrer/ experimente-zur-spektroskopie/. [Accessed: 14-Jan-2019].

[20] Haanpalo, J. and Hauta-Kasari, M., "Candy colors." [Online]. Available:

https://www.uef.fi/web/spectral/candy-colors. [Accessed: 12-Dec2018].

[21] Nedovic, V., Kalusevic, A., Manojlovic, V., Levic, S., and Bugarski, B., "An overview of encapsulation technologies for food applications," Procedia Food Science, 1, 1806-1815, Jan. 2011.

[22] Sarndi, I. and Stetina, V., "Anwendung des Klärungsreagens nach Carrez bei der polarimetrischen Bestimmung der Stärke," Zeitschrift für Lebensmittel-Untersuchung und Forschung, 106(2), 142-144, Aug. 1957.

[23] Wicklin, R., "The distribution of colors for plain M\&M candies," 20-Feb-2017. [Online]. Available:

https://blogs.sas.com/content/iml/2017/02/20/proportion-ofcolors-mandms.html. [Accessed: 04-Dec-2018].

[24] Lehmann, G. and Eich, H., Anleitung zur Abtrennung und Identifizierung von Farbstoffen in gefärbten Lebensmitteln, Bonn, Harald Boldt Verlag, 1980.

[25] Kiefer, W., Peica, N., Pavel, I., Rastogi, V. K., and Cinta Pinzaru, S., "Vibrational characterization of E102 food additive by Raman and surface-enhanced Raman spectroscopy and theoretical studies," Journal of Raman Spectroscopy, 36, 657-666, Feb. 2005.

[26] Kolev, T. M., Velcheva, E. A., Stamboliyska, B. A., and Spiteller, M., "DFT and Experimental Studies of the Structure and Vibrational Spectra of Curcumin," International Journal of Quantum Chemistry, 102, 1069-1079, Jan. 2005.

[27] Kvittingen, E. V., Kvittingen, L., Sjursnes, B. J., and Verley, R. "Simple and Inexpensive UV-Photometer Using LEDs as Both Light Source and Detector," Journal of Chemical Education, 93(10), 1814-1817, Oct. 2016.

[28] Tymecki, Ł., Pokrzywnicka, M., and Koncki, R., "Paired emitter detector diode (PEDD)-based photometry - an alternative approach," Analyst, 133(11), 1501-1504, Oct. 2008. 